\title{
Tropical Forest and Carbon Stock's Valuation: A Monitoring Policy
}

\author{
Thiago Metzker, Tereza C. Spósito, Britaldo S. Filho, \\ Jorge A. Ahumada and Queila S. Garcia
}

Additional information is available at the end of the chapter

http://dx.doi.org/10.5772/48355

\section{Introduction}

Carbon is the fourth most abundant element on Earth. It is estimated that the world's forests store 283 gigatonnes $(1 \mathrm{Gt}=1$ billion tons) of carbon in their biomass alone and $638 \mathrm{Gt}$ of carbon in the ecosystem as a whole (to a soil depth of $30 \mathrm{~cm}$ ). Thus, forests contain more carbon than the entire atmosphere. Carbon is found in forest biomass and dead wood, as well as in soil and litterfall [1]. Consequently, changes in forest carbon storage, resulting from a shift in land use, have a significant impact on global climate change [2].

Changes in climate occur naturally, through processes operating on a geologic time scale. For example, the main species presently inhabiting the planet have survived climate changes during the Pleistocene, adjusting their geographical distribution to weather conditions. However, the speed and magnitude of changes that have been occurring in the Earth's climate system since the Industrial Revolution are currently of great concern. In 1991, the Intergovernmental Panel on Climate Change (IPCC) published a first report about global temperature increases caused by the intensification of the greenhouse effect. After this official announcement, the IPCC has established different working groups with scientists from various parts of the world in order for them to meet and compile as much information as possible and to update scientific predictions about the climatic future of the planet. The reports that have been produced by the international scientific community are considered as the main reference for global climate change.

Currently, scientific societies question the capacity of the present biota to tolerate such changes, in an environment that has been highly fragmented by human intervention and where what is still left intact is confined within protected areas. Changes within biota can result in changes in the ecosystem services they provide. Human well-being depends directly and indirectly on the environmental services provided for free by the natural world, 
including climate regulation, soil formation, erosion control, carbon storage, nutrient cycling, provision of water (both quality and quantity), maintenance of hydrological cycles, preservation of genetic resources, scenic beauty, among others [3]. Furthermore, tropical forests contain $50 \%$ of all world species and are considered mega-diverse environments. Therefore, changes in any of these services can have serious consequences for biodiversity, for the natural carbon cycle and the hydrological cycle, which may in turn alter the world economy and affect the everyday life of humans and other species on the planet.

How can these changes be monitored? One way to monitor biodiversity and carbon stocks over large areas is through the establishment of forest inventories. These are effective tools for estimating the type, amount and condition of forest resources over large areas [4]. The regular collection of measurements within Permanent Monitoring Plots (PMPs), combined with the use of statistical techniques, provide a baseline for assessing changes in the structure and dynamics of a forest and permit the construction of predictive models [5]. In the last decade, there has been a large increase in the installation of PMPs in different tropical forest sites around the world, especially in the Amazon Rainforest, where large monitoring networks (TEAM, PELD, CTFS, RAINFOR, LBA, REDEFLOR, PDBFFE and CIFOR) have been established. These programs increase the level of understanding of ecological systems, transforming the knowledge base [6]. However, there are still serious deficiencies in estimating carbon stocks and other components of other types of tropical forests, types and others components of tropical forests.

Within the current political and environmental international situation it is vital that all countries, whether or not signatories of the Kyoto Protocol, do promote initiatives to monitor their biodiversity and their carbon stocks. These data are strategic for each country because they indicate where and how the management of natural resources can bring benefits to local people (local scale), they support the creation of public policies that can become part of the country's legislation (regional scale) and promote policies for adaptation to an increased vulnerability to climate change (global scale).

This chapter, "Tropical Forest and Carbon Stock's 1 Valuation: A Monitoring Policy", incorporates parts of the TEAM (Tropical Ecology Assessment Monitoring) protocol [7] and the knowledge generated over six years of monitoring permanent plots in an area of the Atlantic Rainforest in Brazil. It aims to discuss the importance of planning and implementation of PMPs, the main techniques used, and the errors associated with them. Biomass, carbon stock calculation techniques and data analysis will also be discussed, among other topics. Data collection and analysis have a greater value when incorporated into natural resource management policies, such as Payment for Environmental Services (PES), which are provided by nature. A comprehensive approach involving stakeholders at all levels, from the local to the global scale, is essential for the success of integrated policies. Each of the topics listed below will be presented with the aid of practical examples, figures and tables, in order to allow readers the opportunity to fully engage with the subject matter and, most importantly, to begin to understand how to apply these practices in their own social and environmental contexts. 


\section{Inventory Data}

\subsection{Methods for establishing Permanent Monitoring Plots (PMPs)}

The establishment of vegetation monitoring networks is a strategy that aims to develop an integrated database through systematized collections using a single monitoring protocol on various sites. In the vegetation network implementation, it is extremely important that the database management team be clear about the questions to be asked and the objectives for the collection of field data. This systemization has implications directly related to the method of collection and the definition of the protocol for implementation and monitoring. The primary analyses to be conducted also must be predefined as they too have a direct impact on the sample design and the means of data collection.

During the planning of a monitoring network, it is important to keep in mind that the key objective is to conduct large-scale analyses that can speak to physiognomy, biomes and wider generalizations. This scale of work is fundamental in order to accomplish robust analyses and to study broad-scale ecological processes. However, it should be noted that local and regional data and publications are also part of this network as they promote the development of local scientific knowledge, along with the participation of the team responsible for the collection of field data. These initiatives encourage cooperation and sharing of experience, in addition to motivating those who are responsible at the local level to continue the work of monitoring once the objectives and results of the initiative are made clear to all involved.

The means of disseminating results should also be defined in the planning phase. For example, during this phase, contact can be made with the editors of scientific journal where there is an intention to publish, in order to establish a connection with the journal and develop credibility for a strong relationship. The sharing of the monitoring protocol, the initial results and the key conclusions at national and international conferences provides visibility for the project and stimulates ongoing discussions with other researchers in the topic area. This interaction and sharing of experience always benefit the project as they increase quality and strengthen key elements. The network planning team should also identify other forms of communication for scientific dissemination, such as specialized documentaries, news networks, community sites and scientific blogs. These promote dissemination and constructive discussion of the conclusions and methods of the published initiative. Another tactic that can make a significant contribution to successful monitoring over the long term by strengthening relationships with local teams is the development of news releases in the local language where the data was collected.

As with any good plan, the protocol must be rigorous. Several protocols for monitoring tropical forests are available including RAINFOR's [8], TEAM's [7] and the Smithsonian's Center for Tropical Forest Science [9]. However, it must also be flexible enough to be adapted and to evolve naturally according to the knowledge generated during the planning process, as well as to the local reality of each site. Ongoing workshops with the local team guarantee that acquired experience is formally recorded, in addition to facilitating the continuous improvement of the protocol by applying experience acquired through its execution in situ. 


\subsection{Geoprocessing techniques for area selection}

Many field procedures involve high costs due to transportation and logistics. Therefore, prior to any field procedure, errors in area selection can be minimized by careful planning using GIS techniques. In addition to playing an important role in the preliminary phase (planning), these tools are also very useful in the data analysis phase. When these instruments are used extensively by a qualified professional, significant economies of time and financial resources can be achieved.

After clearly defining the objectives for the implementation of the monitoring network, the next phase is the selection of potential areas to house the plots. The use of GIS allows for a more confident selection of the target areas since it works with georeferenced bases and shapes which allow for simulation of PMPs implemented in practically any location in the world. These areas can be selected by process of elimination from those that, for example, do not have the required attributes or by selection of multiple criteria that involves interpolation of various bases. Through experience acquired in the implementation and monitoring of PMPs, we understand that the minimal criteria for exclusion of target areas for monitoring include:

- Areas that possess accentuated declivity;

- Areas that are not easily accessible and complicate field logistics;

- Areas with creeks, swamps, lakes and rivers;

- Areas that have significant spatial heterogeneity;

- Areas that have variations in the type of soil.

Assuming that the objective of monitoring is to evaluate the temporal dynamics of primary vegetation areas, the areas that are not located in Conservation Units can be excluded first. It is understood that forested areas protected by law in any part of the world represent the highest percentage of protected primary areas. After this first filter, the layers or shapes that meet the exclusion criteria cited above are applied. This type of cut is made relatively quickly, while still in the office, but can reduce a universe of potential samples by more than $90 \%$ in certain regions of the world, thus optimizing the accuracy and use of the project's financial resources.

Following elimination of the areas not selected for the sample, the professional responsible for the GIS technology should create polygons capable of housing the future PMPs so that random samples can be selected from within the universe of possible options, thus establishing statistical confidence for the sample. Another important point is that the PMPs should be replicated in areas where there is similar physiognomy, so that means, errors and reliable statistics can be obtained.

It is of fundamental importance for the field team that thematic maps be developed by the GIS team. These maps should be easy to visualize and understand, with current satellite images and superimposed colored sketches of the PMPs in various layers. Essential factors for successful field work include the standardization of symbols, language and scale of work, as well as pre-definition of a standard datum, and being in a system of unique 
coordinates compatible with the use of local GPSs. The field maps should also be plasticized to avoid stains and tears which can often occur with the use of these materials in the middle of the forest.

\subsection{Choosing target areas}

The field team should also be very clear about the objective of monitoring. When the project's primary issue is related to the dynamics of areas in recovery or to the differences between primary and secondary vegetation areas, area selection involves different parameters. When the question is focused on temporal variations in areas of intact vegetation in the climactic stage, area selection will be directed primarily toward areas protected by legal mechanisms in each region, ensuring that there will be no interference in the plot throughout the years of monitoring. Depending on the objective, criteria for intersite analysis can also be established, such as a latitudinal gradient temperature or rainfall gradient, soil gradient, etc.

Once all of the criteria have been established, the field team should depart in order to locate and validate the target areas in situ. In addition to being accompanied by local guides, the team should be supplied with basic field supplies as well as thematic maps developed by the GIS team, a GPS, a compass, and a camera for the validation or invalidation of areas previously defined by the GIS team. Additionally, the field team should have in your GPS all points and layers that were previously prepared by the GIS team. For example, see [10] for a complete data transfer protocol.

It is important that the field team be fully trained on the monitoring protocol and have the ability to independently decide at any given moment if an area truly possesses the defined selection criteria or if it would be better to search for a new area. This decision is a key since all monitoring throughout the years ahead will depend on the correct choice and demarcation of these plots. In order to select the best areas for PMPs to be implemented, various factors should be taken into consideration, including the homogeneity of the forest typology to be sampled, the existence of water courses, logistics, access, type of soil and inclination of the terrain.

Due to difficulties of orientation and localization in interior bush areas, the geographical coordinates should be checked and the location of the field team confirmed upon arrival at the target area. Once the location has been verified, a marker should be placed in the ground (a PVC tube of about $1.3 \mathrm{~m}$ can be used) to be the point of coordinates $0,0(\mathrm{X}, \mathrm{Y})$, which will serve as a reference point for the validation of the area as well as for future plot implementation. This point will be used to evaluate the area to decide whether or not it will be selected for PMP implementation. Thus, using a compass, the direction of the course should be read, so that the angle of the directions has a difference of $90^{\circ}$ (straight angle). The course is followed in the first direction $(X)$, remaining aligned with the lead angle on the compass, stopping every 20 meters to check the coordinates and the direction of the course. In the field, detours are very common during a walk/hike due to natural obstacles such as fallen trees and branches, the presence of lianas or holes in the ground, or large trees that 
have to be circumvented. It is important in this verification phase, as well as in the PMP implementation phase, that knives and scythes are not to be used to open trails or forest passages as they can have a long term impact with significant implications on the dynamics of vegetation. Thus, when faced with a natural obstacle, the ideal would be for the team to circumvent it and return to the defined course in order to continue with area verification.

The team should be aware of sudden changes in the type of soil, the existence of accentuated declivity that was not possible to identify in the satellite images, or any other element that strongly differentiates the landscape and that could negatively impact the monitoring or the homogeneity of the plot. This should be recorded in a designated worksheet in order to justify the decision not to use the area in question. Once line $X$ has been verified, the same procedure is conducted with line $\mathrm{Y}$ beginning from ground zero. If an area does not possess significant heterogeneity, the selection of the plot must be validated, assigning a number and a syllable to be used throughout the entire period of monitoring and analysis of that area (e.g. 01-LP).

\subsection{Implementation of PMPs in the field}

Once the entire validation process is complete, the actual marking of the PMP in the field is undertaken. On the day prior to departure, a checklist should be reviewed of all equipment required for field implementation, such as PVC tubes, rubber hammer, colored tape, polypropylene cord, compass, GPS, binoculars, clipboard, collection worksheets, plastic bags, masking tape, pencils, erasers and pens. In addition to support materials, specialized clothing must also be taken, such as boots, leggings and field jackets (with many pockets). The PMP implementation team should be comprised of at least 4 people, primarily to divide the weight of materials to be taken to the selected PMP area, as the tubes or stakes used to mark the chosen spots are very heavy and bulky.

Upon arrival at the PMP location previously marked as 0,0 , a suitable location to leave all of the equipment should be identified, as well as an appropriate place to have snacks or lunch while in the field. This location, named "Support Station - SS" should be located in the outlying area of the PMP so that it does not interfere with the vegetation to be monitored on the plot. The ground should be covered by a light blue tarp (or any color that strongly contrasts the forest floor), upon which all of the equipment should be placed to avoid loss. Again, it is imperative that the team be careful not to allow any type of vegetation (lianas, branches or shrubs) to be cut during plot implementation.

In the following example, we simulate the implementation of a 1 ha PMP $\left(10.000 \mathrm{~m}^{2}\right)$ according to the TEAM protocol for vegetation monitoring [7]. The size of the PMP will depend on the initial objective outlined by the team responsible for managing the project. The size of 1 ha is widely used in permanent plots whose objectives are related to monitoring the dynamics and carbon stocks for the site in question.

Starting at 0,0, two baselines $(X, Y)$ should be projected, at $90^{\circ}$ perpendicular angles, which will serve as reference points throughout the PMP implementation. Each baseline should be spiked every 20 meters, with their distance verified using a measuring tape and direction 
verified by reading the course angle on the compass. After the 6 spikes for each baseline have been duly marked and inserted into the ground, the entire line should be measured to confirm its length, which should be a total of 100 meters. Each spike placed every 20 meters should be sequentially numbered, as well as having its Cartesian coordinates on the plot recorded (e.g. 20, $0 ; 40,0 ; 60,0 ; \ldots$ ). Once line $X$ has been completed, the formation of line $Y$ can be undertaken using the same procedures previously followed.

Once the two baselines have been formed, the internal squares of the PMP can be developed. In order to close a PMP, two basic methods can be used: creating 5 lines parallel to baseline $Y$ (Figure 1-B) or creating small $400 \mathrm{~m}^{2}$ squares, forming sequential lines until the entire PMP is closed (Figure 1-A).
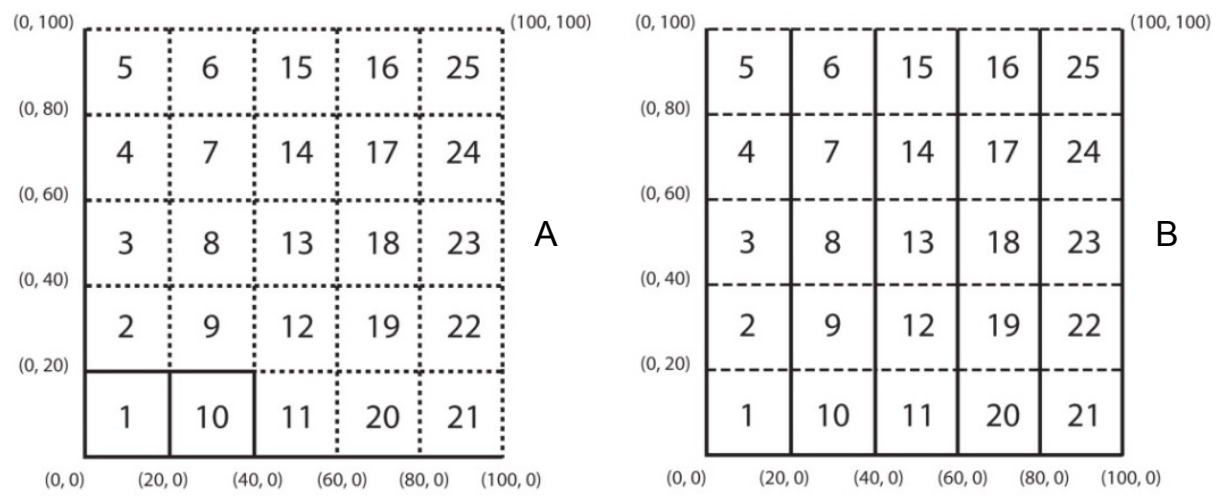

Figure 1. Sample structure of the Permanent Monitoring Plot (PMP), with 25 sub-plots. A - Means of closure using squares; B - Means of closure using lines. Adapted from TEAM (2010).

\subsection{Marking trees}

After marking the PMP, the individuals to be monitored are marked and data collection is undertaken. For studies related to long-term monitoring of the structure and dynamics of vegetation, it is common for the sample to include all individuals in the forest that have $\mathrm{DBH} \geq 10 \mathrm{~cm}$ (Diameter at Breast Height). For studies of biomass and carbon stocks, individuals with $\mathrm{DBH}<10 \mathrm{~cm}$ are not included, due to their low contribution to the total stocks of the PMP. In general, if the objective is to monitor changes in floristic composition and the biodiversity of the PMP, these smaller individuals should be incorporated into the monitoring.

In this case, all of the trees palms and lianas with a $\mathrm{DBH}$ greater than or equal to $10 \mathrm{~cm}$ should be marked and measured. The POM (Point of Measurement) is the point on the tree or liana where their respective diameters are measured. The POM is marked at $1.30 \mathrm{~m}$ with the help of a PVC tube graded at $1.60 \mathrm{~m}$ and $1.30 \mathrm{~m}$ to avoid error related to the different heights of the field markers. However, for individuals with tabular roots, sapopemas or buttress roots, the POM should be identified at $50 \mathrm{~cm}$ above the highest root (Figure 2). This is a valid 
change since it is common in forest inventories to find all stems with their DBHs measured at $1.30 \mathrm{~m}$. When these data are inserted into allometric equations to calculate biomass, they overestimate biomass, increasing the standard error of these calculations [9-13].

In the case of trees that have many deformities at the POM, a modular ladder up to 12 meters ( 4 modules of 3 meters each to make it easy to transport in the forest) should be used so that the best location on the tree can be selected for diameter measurement (Figure 2 and Figure 3). Leaning or fallen trees should have their $\mathrm{DBH}$ measured following the methodology above; however, the distance from the base should be measured from the underside of the tree (Figure 2) in order to obtain an accurate distance. For trees with multiple trunks, where forking occurs below $1.30 \mathrm{~m}$, each trunk should be considered a separate individual (Figure 2), with the number of measurements matching the number of trunks for the tree.

Once the best area for $\mathrm{DBH}$ measurement has been selected, it should be painted with yellow paint. This can also be done with a type of stamp (stencil) that can be made out of a sheet of hard plastic that is cut in the center in the following dimension: $20 \times 3 \mathrm{~cm}$. After selecting the location to be painted, the stamp (stencil) is placed on the tree and the POM is painted (Figure 3). In addition to facilitating field work, this stamp also standardizes the width of the paint marking on the trees, thus reducing the possibility of errors in future tree measurements.

This marking should be re-done every two years so that the specific POM is not lost. In order to avoid errors related to POM marking, the height at which the POM is marked should be recorded in a designated field worksheet. This procedure, along with painting the POM, guarantees that the measurement will be done at the exact same point during recensus throughout the monitoring period.

All of the individuals selected should be marked with nails and aluminium tags using increasing numbers according to the layout within the PMP. The nail should always be a distance of $40 \mathrm{~cm}$ from the POM so that the nail hole does not damage the trunk and consequently alter the POM. It is very common to see trees in the forest that have significant deformities resulting from a small nail hole. Bacteria and pathogens can enter through this small orifice and cause significant stress to tree trunks. Another important point is that the nail should be pointed downward whereby the tag is touching the head of the nail, since it is common to see trees that envelop around the tags over time when the tags had been touching the trees themselves.

After numeration and marking are complete, each individual should be identified at the highest taxonomic level possible in the field. It is highly recommended that photos be taken of the collected branches and that a collection of each species within the PMP be maintained as a botanical collection specific to each region. The data should be recorded in field worksheets and branch samples that are not identified should be taken for laboratory activities, herbarium consultations and completion of taxonomic identification by specialists. All field collections should be labelled with masking tape, recording their PMP number and reference code. 

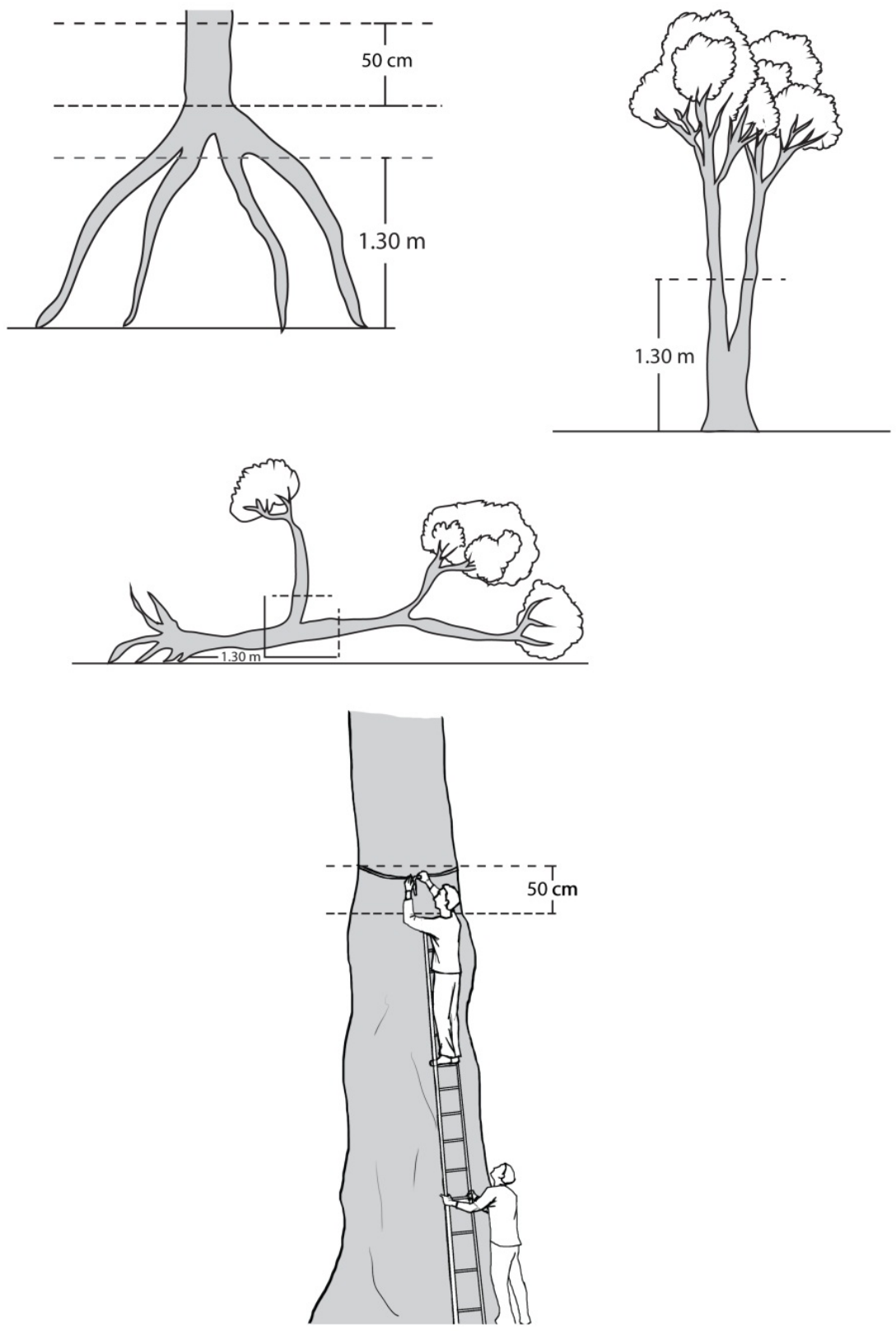

Figure 2. Details for marking trees with deformities in the field. A - For tabular roots, the POM is measured $50 \mathrm{~cm}$ above the last root; $\mathrm{B}$ - For multiple trunks, each is measured as a separate individual, provided the forking is below $1.30 \mathrm{~m}$; C - For fallen trees, the distance is taken from the underside; $\mathrm{D}$ For tall trees, the measurement should be done with the support of modular ladders. 


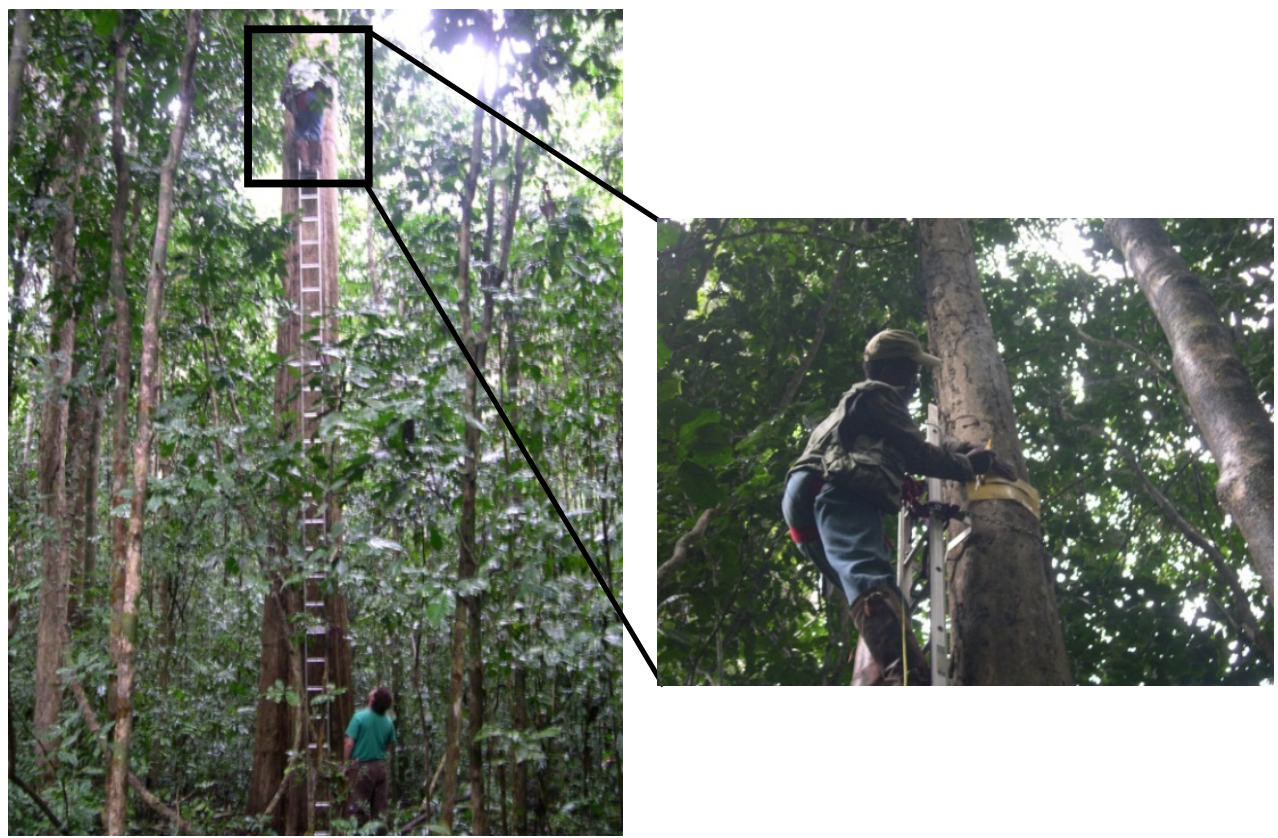

Figure 3. Details of marking big trees at Rio Doce State Park: Use of a modular ladder up to 12 meters and POM painting process using a stencil. Source: Metzker, T.

With the collection and identification of botanical material, local guidebooks can be developed for the identification of trees registered within the PMPs. The guidebook could include photos of dried plants, taxonomic identification, location of the species, whether or not there are medicinal purposes, and details about flowers or fruits. In collaboration with local experts, the production of this type of material strengthens relationships between project managers and the execution team, in addition to producing registered material that is easily understood by the local population.

\subsection{Calibration of diameter tape}

As a result of the measurement process, diameter tape can become stretched or it may come from the factory already with small defects. Considering that the annual growth rate of a tree stratum in the forest is $\sim 0.2 \mathrm{~cm} /$ year [14] small measurement errors can have a strong impact on the final results. In order to avoid this type of error, the diametric tape should be calibrated using an aluminium ruler prior to each census, thus maximizing the level of precision in the results.

\subsection{Measurement calibration}

Errors in reading the diametric tape or errors in the position of the tape on the can be common during the census, negatively impacting the processing and analysis of data. 
Therefore, prior to each census, it is also necessary to calibrate the technician responsible for measuring the trees.

On the first day of the census, all possible measurements should be completed within a given PMP. One or two days later, the same person who measured the trees on day one should return to the same area and re-measure all of the previously measured trees. The results are considered good if the one measuring the trees obtains a minimum of $70 \%$ accuracy, or $90 \%$ with less than $1 \mathrm{~mm}$ of error. If these parameters are not reached, the procedure is repeated, even with others doing the measuring, until the required precision is obtained. The objective in each phase is to minimize potential errors that generally occur in field activities and which substantially impact data analysis.

\subsection{Census and re-census}

The measurement of the individuals located in a PMP is the heart of the entire initiative. The measurements conducted during the first census should be done with careful attention so that the complete methodology for measurement and marking is constantly being verified and validated. Despite the fact that there are technicians responsible for data collection who are fully trained in the methodology, a copy of the measurement protocol and its specifications should be available for consultation in the field.

It is important to remember that the period for plot measurement (completion of the first census or re-censuses) should be defined by the analysis of a series of rainfall in the region under study so that the measurements can always be done at the same time of year, that is, in the month that has the least amount of precipitation. This strategy seeks to take advantage of the best transportation logistics, generally by ground, and to avoid the influence of rain in the diameter measurements since tree bark can become saturated with water, thus affecting/falsifying growth data.

For the individual measurement of trees, it is recommended that diametric tape (e.g. Diameter Tape - Forest Suppliers) be strictly used. The use of tapes that measure the circumference of individual trees, in order to later convert to diameter, increases estimation errors. The technician responsible for measurement should note, tree by tree, any loose bark, lichens, lianas or other factors that could impact diameter measurement. The technician cleans the measurement area by passing his/her hand along the trunk and then runs the diametric tape around it. Also responsible for worksheet data, the technician should seek to assist the one who is measuring the trees, primarily during the evaluation of large trees, in order to verify the correct position of the tape and to determine if there is anything between the tape and the tree.

During the annual re-censuses, the technician responsible for recording data in the worksheets should pay even greater attention to the data that are found to be divergent from the previous year's records, which could likely be due to an error in reading the diametric tape. If an error is found, the technician should ask for a re-measurement and a rereading of the diameter for recording in the worksheet. 
Another important activity undertaken during the re-censuses is an active search throughout the PMP for new individuals to be included in the sample (recruits) and individuals that no longer exhibit vegetative activity (dead). All of the new trees, palms and lianas that have met the inclusion criteria $(\mathrm{DBH} \geq 10 \mathrm{~cm})$ are included in the sample and the same marking methodology is followed. Individuals marked in the first census but which, during the re-census, did not exhibit vegetative activity or were not found after a detailed sweep of the plot, should be considered dead.

It is also possible that trees that had died in the previous year show activity through diametric growth or new growth. In this case, the processing worksheet should be modified, correcting the data recorded the previous year and including this individual once again in the sample since it was not actually dead.

\section{Analyzing data}

\subsection{Tabulation of data}

For all field activities related to planning, implementation and monitoring of PMPs, there should be specific worksheets. The standardization of the entry of information that will be generated is of fundamental importance to guarantee the quality of the data. Each worksheet should include the following information at minimum:

- $\quad$ PMP name and abbreviation;

- Complete date when the collection was done;

- Names of each of the team members;

- Number of each individual;

- Registration number of the sub-plot to which each individual belongs;

- Data related to the POM and DBH;

- Pertinent observations.

Upon completion of the field work, all of the worksheets used should be digitized, scanned, and saved in a digital file and then stored in a dry, safe place. These procedures assure that the original worksheets can be consulted in the case of duplicate or conflicting information, when typing errors occur, or when mistakes are made in noting information in the field. After digitizing the worksheet data, the new worksheets should be printed and evaluated by pairs for accuracy, followed by the correction of any confirmed errors.

\subsection{Spatial mapping}

Spatial mapping of the individuals marked in the PMPs allows for the possibility of analyses of the distribution of species or guilds in the forest. For these analyses, indices of aggregation, such as Morisita [15] or McGuinness [16], can be used, thus defining the spatial distribution of the individuals as aggregate, random or regular. This knowledge is fundamental to ecological analyses as it facilitates an understanding of how a certain species uses available resources in the forest. While the aggregation factor can vary within a species, 
in different diametric classes, it shows how the life stages of an individual can change the way it uses an available resource.

For mapping, each individual should have its Cartesian coordinates $\mathrm{X}$ and $\mathrm{Y}$ measured in the PMP. The distances can be measured using a 50 meter measuring tape or a digital measuring stick. It is important that a compass always be used to support the measurements so that the distances are consistently taken in a straight line with respect to the position within each sub-plot. In the example below (Figure 4), the individual marked in the PMP has Cartesian coordinates of $X=56.2$ meters and $Y=74.3$ meters.

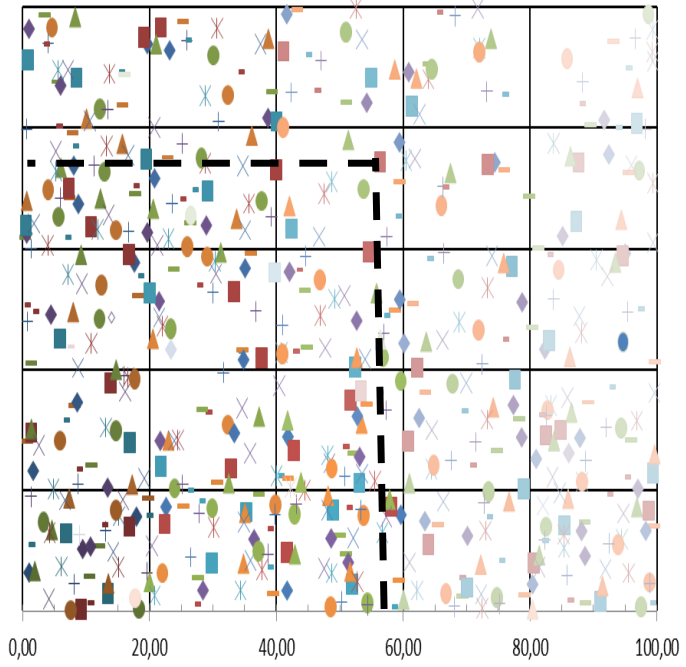

Figure 4. Example of the result of spatial mapping of the field individuals within the PMP at Rio Doce State Park - Minas Gerais, Brazil.

\subsection{Estimates of biomass and carbon stocks}

The estimates of aboveground live biomass and the resulting carbon stocks can be obtained using two key methods. The first, based on destructive sampling (direct method), involves cutting, drying and weighing separately (roots, trunk and leaves) all of the trees in a specific area. This technique becomes unviable in the case of monitoring since it can damage the sample over the life of the vegetation. The second method (indirect method) consists of estimating biomass and carbon stocks by measuring field variables without having to fall the tree. In this case, DBH data and/or total height of the trees $(\mathrm{Ht})$ and/or specific density of the $\operatorname{wood}(p)$ are inserted into previously developed allometric equations in order to estimate the biomass and carbon stocks of the PMP.

Table 1 shows examples of allometric equations already developed and that can be used to calculate biomass. The selection of the best equation should be based on the objective of the project and on the questions to be answered. Allometric models that offer greater precision should be given preference [17]. 


\begin{tabular}{|c|c|c|}
\hline Types & Allometric Equations & $\mathbf{R}^{\mathbf{2}}$ \\
\hline Wet Forest [18] & $\operatorname{EXP}\left(-2.557+0.940 * \operatorname{LN}\left(p * D B H^{2} * \mathrm{Ht}\right)\right)$ & 0.99 \\
\hline Moist Forest [18] & $\operatorname{EXP}\left(-2.977 * \mathrm{LN}\left(p * D B H^{2} * \mathrm{Ht}\right)\right)$ & 0.99 \\
\hline Dry Forest [18] & $\operatorname{EXP}\left(-2.187+0.916 * \mathrm{LN}\left(p * D B H^{2} * \mathrm{Ht}\right)\right)$ & 0.99 \\
\hline Palms [19] & $\operatorname{EXP}\left(\left(5.7236+0.9285 * \mathrm{LN}\left(D B H^{2}\right)\right) * 1.05001\right)$ & 0.82 \\
\hline Lianas [20] & $10^{3}$ & 0.95 \\
\hline Amazon [21] & $\operatorname{EXP}(0.07+2.17 *(\mathrm{LN}(\mathrm{DBH})))$ & 0.92 \\
\hline Amazon [21] & $\operatorname{EXP}(-1.754+2.665 * \mathrm{LN}(\mathrm{DBH}))$ & 0.90 \\
\hline Tree ferns [22] & $-4266348 /(1-(2792284 \operatorname{EXP}(0.313677 * \mathrm{Ht})))$ & 0.88 \\
\hline Wet Forest [23] & $\operatorname{EXP}\left(21.297-6.953(\mathrm{DBH})+0.74\left(D B H^{2}\right)\right)$ & 0.91 \\
\hline
\end{tabular}

[18] - Chave et. al. (2005);

[19] - Nascimento \& Laurance (2002);

[20] - Gerwing \& Farias (2000);

[21] - Higuchi et. al. (1998);

[22] - Tiepolo et al. (2002);

[23] - Brown et al. 1997.

Table 1. Example of allometric equations used to estimate the aboveground biomass $(\mathrm{kg})$ of trees, palms and lianas in different tropical forest types. DBH - Diameter at breast height; Ht - Total height; and $\mathrm{p}$ - Wood mean density $\mathrm{g} / \mathrm{m}^{3}$.

In order to conduct accurate comparisons with other areas or to serve as a potential indicator of carbon stocks for a specific region, simpler allometric equations with only one variable - DBH can be used [17]. In this case, it is not necessary to collect data related to the height or wood density of individuals, resulting in the inventory being completed much faster. An important detail regarding the selection of the equation is that the results for some are fresh biomass data, while for others they are dry biomass data, and still others provide results as carbon quantity.

As previously mentioned, the ideal would be to use an allometric model that provides the highest degree of confidence. The best model has to explain most of the variation in the data or has the lowest AIC (Akaike Information Criterion). In the most cases, equations that use multiple entries with 3 variables per individual $(\mathrm{DBH}, \mathrm{Ht}$ and $p$ ) are better. $\mathrm{DBH}$ data are easily collected as previously outlined. The data related to tree height are generally complicated to collect due to error associated with height estimations, in addition to the need for greater time in the field, which results in inventories having higher costs. In order to optimize this work, an estimate of tree height can be used by creating an allometric equation adjusted by the diametric and height measurements of a specific number of trees in the plot (Figure 4). This requires the collection of height data for a certain part of the plot. These data should be collected with the greatest precision possible, using cords, ladder or equipment such as a rangefinder. It is recommended that height be measured for a random sample of $20 \%$ of the individuals of a PMP in order to later relate them to the diameters, 
producing an equation for site-specific heights (Figure 4). In order to collect data for specific wood density, there are some protocols for extracting and obtaining these values for each tree in a PMP. With a view to obtaining economies of time and project resources, existing databases can be used, for example, Global Wood Density Database [24, 25], which makes available a series of wood density values for species that exist in almost every part of the world.
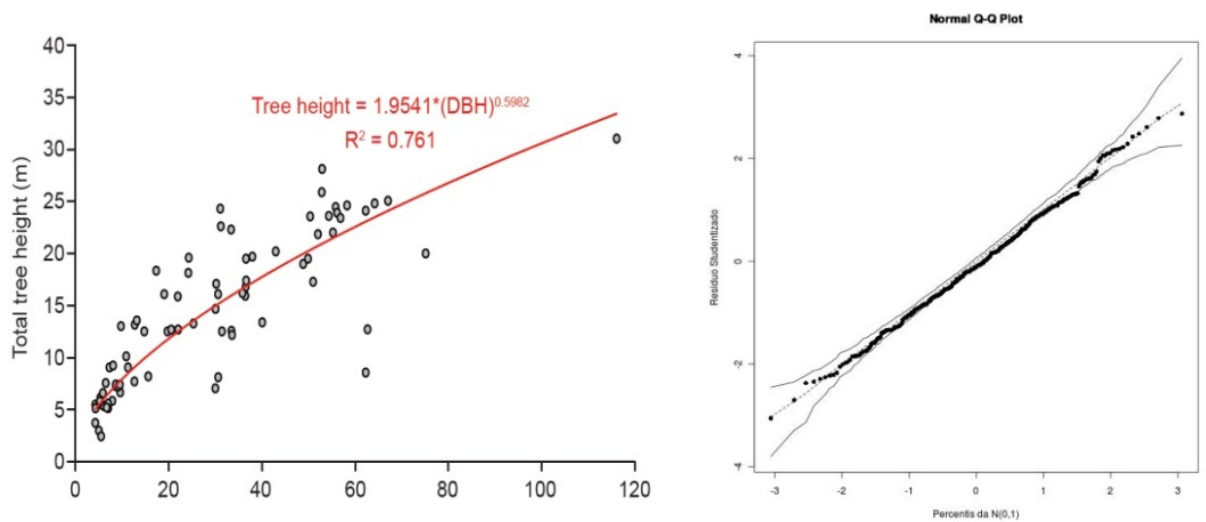

Figure 5. Examples of the development of a site-specific equation for the calculation of height using tree diameters [17] and of equation adjustment using the observance of the normality of residues.

With biomass calculated, many different possibilities for analysis become available. For example, comparisons of biomass can be done between primary and secondary areas, between one year and another, and total biomass can be calculated for the PMP and extrapolated to large forested areas of the same typology. In addition to comparing the relative data to the average annual increment of biomass (or of carbon) of a PMP, analyses of the change in biomass between years can also be conducted. This can be achieved by subtracting the biomass in year one from the biomass in year 0 , remembering that this biomass value should include the biomass of recruits in year 1 while the biomass of individuals considered to be dead is subtracted. Another factor that can be considered is the number of days between each census in order to standardize the calculations for a specific period. For example, for 1 year, the following equation would be used:

$$
\left(\frac{A G B t 2-A G B t 1}{D T t 2-D T t 1}\right) * 365
$$

where AGBt2 refers to biomass in year 2, and AGBt1 to biomass in year 1. DTt2 refers to the date the census was taken in year 2, and DTt1 to the date the census was taken in year 1 (D. Clark personal communication).

Table 2 shows the data for aboveground biomass (AGB) for different neotropical forest sites (adapted by Alves, 2010 [26]). The highest values were primarily found in the Brazilian Amazon (Manaus and Santarém). 


\begin{tabular}{|c|c|c|}
\hline Sites & AGB (Mg.ha-1) & Reference \\
\hline $\begin{array}{l}\text { Submontane moist semideciduous } \\
\text { secondary forest, Marliéria, Brazil }\end{array}$ & 92.0 & [27] Metzker et al. (2011) \\
\hline $\begin{array}{l}\text { Submontane moist semideciduous } \\
\text { secondary forest, Marliéria, Brazil }\end{array}$ & 107.0 & [27] Metzker et al. (2011) \\
\hline $\begin{array}{l}\text { Lowland seasonally dry forest, } \\
\text { Mexico }\end{array}$ & 109.0 & [28] Vargas et al. (2008) \\
\hline $\begin{array}{l}\text { Lowland wet forest, La Selva, Costa } \\
\text { Rica }\end{array}$ & 148.7 & [11] Clark and Clark (2000) \\
\hline $\begin{array}{l}\text { Seasonally flooded forest (Restinga), } \\
\text { Ubatuba, Brazil }\end{array}$ & 154.0 & [26] Alves et al. (2010) \\
\hline Montane wet forest, Venezuela & 157.0 & [29] Delaney et al. (1997) \\
\hline Montane moist forest, Venezuela & 173.0 & [29] Delaney et al. (1997) \\
\hline $\begin{array}{l}\text { Submontane moist semideciduous } \\
\text { primary forest, Marliéria, Brazil }\end{array}$ & 174.0 & [27] Metzker et al. (2011) \\
\hline Lowland moist forest, Venezuela & 179.0 & [29] Delaney et al. (1997) \\
\hline Lowland moist forest, BCI, Panama & 179.1 & [30] DeWalt and Chave (2004) \\
\hline $\begin{array}{l}\text { Submontane moist semideciduous } \\
\text { primary forest, Marliéria, Brazil }\end{array}$ & 179.8 & [27] Metzker et al. (2011) \\
\hline $\begin{array}{l}\text { Lowland moist forest, Ubatuba, } \\
\text { Brazil }\end{array}$ & 198.4 & [26] Alves et al. (2010) \\
\hline $\begin{array}{l}\text { Submontane moist semideciduous } \\
\text { primary forest, Marliéria, Brazil }\end{array}$ & 201.0 & [27] Metzker et al. (2011) \\
\hline $\begin{array}{l}\text { Lowland wet fores, La Selva, Costa } \\
\text { Rica }\end{array}$ & 203.2 & [30] DeWalt and Chave (2004) \\
\hline $\begin{array}{l}\text { Lowland forests, SW Amazonia } \\
\text { (Bolivia, Peru) }\end{array}$ & 206.7 & [31] Baker et al. (2004) \\
\hline $\begin{array}{l}\text { Lowland forests, NW Amazonia } \\
\text { (Peru, Ecuador) }\end{array}$ & 220.8 & [31] Baker et al. (2004) \\
\hline $\begin{array}{l}\text { Submontane semideciduous forest, } \\
\text { La Chonta, Bolivia }\end{array}$ & 236.6 & [32] Broadbent et al. (2008) \\
\hline $\begin{array}{l}\text { Submontane moist forest, Ubatuba, } \\
\text { Brazil }\end{array}$ & 239.3 & [26] Alves et al. (2010) \\
\hline Lowland wet forest, Manaus, Brazill & 240.2 & [30] DeWalt and Chave (2004) \\
\hline $\begin{array}{l}\text { Lowland moist forest, Rio Branco, } \\
\text { Brazil }\end{array}$ & 244.1 & [33] Vieira et al. (2004) \\
\hline Lowland moist forest, BCI, Panama & 260.2 & [34] Chave et al. (2003) \\
\hline $\begin{array}{l}\text { Montane moist forest, Ubatuba, } \\
\text { Brazil }\end{array}$ & 262.7 & [26] Alves et al. (2010) \\
\hline
\end{tabular}




\begin{tabular}{|l|c|c|}
\hline $\begin{array}{l}\text { Lowland forests, Central \& Eastern } \\
\text { Amazonia (Brazil) }\end{array}$ & 277.5 & [31] Baker et al. (2004) \\
\hline $\begin{array}{l}\text { Lowland moist forest, Santarem, } \\
\text { Brazil }\end{array}$ & 281.2 & [33] Vieira et al. (2004) \\
\hline $\begin{array}{l}\text { Lowland semideciduous forest, } \\
\text { Roraima, Brazil }\end{array}$ & 292.1 & [35] Nascimento et al. (2007) \\
\hline $\begin{array}{l}\text { Lowland moist forest, Santarem, } \\
\text { Brazil }\end{array}$ & 294.8 & [36] Rice et al. (2004) \\
\hline $\begin{array}{l}\text { Lowland moist forest, Santarem, } \\
\text { Brazil }\end{array}$ & 298.0 & [37] Pyle et al. (2008) \\
\hline $\begin{array}{l}\text { Lowland moist forest, Rondonia, } \\
\text { Brazil }\end{array}$ & 306.8 & [38] Cummings et al., 2002 \\
\hline $\begin{array}{l}\text { Lowland wet forest, Manaus, Brazil } \\
\text { [39] Castilho et al. (2006) }\end{array}$ & 307.6 & [40] Chave et al. (2001) \\
\hline $\begin{array}{l}\text { Lowland wet forest, Nouragues, } \\
\text { French Guiana }\end{array}$ & 317.0 & [19] Nascimento and Laurance \\
\hline (2002)
\end{tabular}

Table 2. Estimates of aboveground biomass in different forest typologies on neotropical sites. Adapted by (Alves et al. 2010 [26]). AGB data (Mg.ha-1).

\subsection{Recruitment and mortality rates}

Calculations of the annual rates of Recruitment (Eq. 2) and Mortality (Eq. 3) can be done using the equations by Sheil and Mail [42]. These rates are an excellent indicator of forest dynamics, providing a solid understanding of forest behaviour as it is affected by seasonal events causing variations in water availability, or by extreme climatic events or to conduct multiple comparisons. Since, in reality, everything depends on the proposed objective, forest dynamics can be compared, for example, between those individuals that belong to the higher diametric classes and those who belong to the lower, or the behaviour between different species, among others.

$$
R=\left[\left(\left(\frac{N o+N r}{N o}\right)^{\left(\frac{1}{t}\right)}\right)-1\right] * 100
$$




$$
M=1-\left[\left(\left(\frac{N o-N m}{N o}\right)^{\left(\frac{1}{t}\right)}\right)\right] * 100 ;
$$

where: No equals the number of individuals at time 0 ; $N m$ is the number of dead individuals between the interval; and $N r$ is the number of individuals recruited in the same time interval $(t)$.

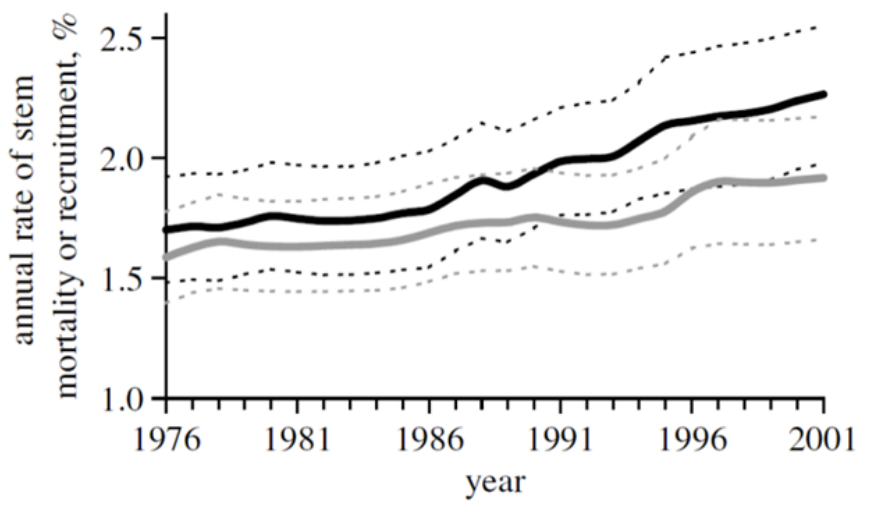

Figure 6. Example taken from Phillips et al., (2008) [43] referring to the analysis of mortality rates (grey lines) and recruitment rates (black lines), using a monitoring time period of 25 years. Solid lines are means and dotted lines are 95\% CIs.

\section{The valuation of tropical forests}

In this section, we will explain how to assign value to carbon stock estimates taken from collected data on PMPs. We will also discuss issues regarding the Payment for Environmental Services (PES), which is provided by tropical forests that are connected with major international protocols and signed agreements.

\subsection{Assigning value}

Forest conservation strategies to be effective, local communities must first be significantly involved and they must believe in the importance of biodiversity to guarantee quality of life. These communities are the key to a conservationist network. The second step is to invest financially in these initiatives. The project should clearly demonstrate that forest conservation efforts are more economical lucrative when compared with the opportunity costs of using the soil in a given region, for example, for cattle-raising. Therefore, investing in the protection of biodiversity in order to encourage the social and economic development of local communities is one of the best long-term conservation strategies for biodiversity and the ecosystemic services it generates.

One of the difficulties in assigning value to biodiversity and the services it offers is how to specifically quantify this value. First, the value of its natural attributes is immeasurable, 
such as the services offered by bees when pollinating plantations throughout the world or the atmospheric regulation offered by forests (see, [44]). Thus, the carbon valuation and commercialization market has an advantage, since the prices per ton are already known by the market. Despite being affected by countries' economic changes, a ton of carbon (sequestered or saved) has its own regulations derived from international agreements, such as the Kyoto Protocol or by mechanisms such as the CDM (Clean Development Mechanism) and REDD (Reducing Emissions from Deforestation and Forest Degradation). Therefore, projects that seek to assign economic value to environmental services can include "carbon valuation" as a more precise indicator of the technical reliability of the project.

Forest projects began to participate in the global carbon credit market when companies partnered in order to preserve forests and plant trees with the goal of neutralizing their greenhouse gas emissions [3]. Due to the initial difficulty of negotiating these credits within a regulated market (compliance market), many of these initiatives looked for the voluntary market [3] and other financial transactions that could neutralize their emissions by trees capturing carbon. These new mechanisms opened the door for a wide variety of carbon projects that include voluntary initiatives as payment for the recovery of degraded areas as a means of neutralizing emissions and even responsibility for conserving existing forest areas.

\subsection{Development of public policies}

These widely diverse ongoing carbon projects have one objective in common: to take advantage of existing market mechanisms in order to assign economic values to rainforests. Today, the REDD+ mechanisms is considered one of the most interesting since it focuses on creating an institutional structure and economic incentives required for developing countries to substantially reduce their $\mathrm{CO}_{2}$ emissions resulting from deforestation and forest degradation [45].

A practical example of implementing public policies connected to carbon projects is the program called Bolsa Floresta (Forest Fund), created by the state of Amazonas through Law no. 3135 on 05/06/2007. Through this initiative, the Government pays R\$50 ( USD \$30) per month to registered families who live in State Conservation Units and who have signed a collective agreement to stop deforestation [45]. In the state of Minas Gerais, the Government created an initiative called Bolsa Verde (Green Fund) (Law no. 17.127 in 2008), whose objective is to help conserve native vegetation cover in the State by paying property owners for environmental services if they already preserve or are committed to restoring native vegetation on their properties. In this case, the financial incentive is relative to the size of the protected area, which is a priority for family farms and rural producers. Thus, the REDD+ has a comprehensive rural planning strategy that values rainforests and their recovery, as well as supporting the sustainable development of rural livelihoods [45] and facilitating true socio-environmental gains.

For all of these initiatives works, there must also be reliable data on existing carbon stocks to serve as a baseline for the projects. Permanent Monitoring Plots are technically considered 
to be the best way to obtain these data. For forest recovery projects, where it is not possible to implement PMPs, they can be implemented using adjacent areas or existing data can even be used to extrapolate biomass values. During the monitoring of carbon projects, the random distribution of PMPs serves as a statistically equivalent sample area for forest recovery monitoring. As an example of other monitoring sites using a standardized methodology we can cite the TEAM network (http://teamnetwork.org/) which has more than 15 monitoring sites in tropical forests. In Brazil we can cite two of these sites: Manaus, Caxiuanã, which have 05 PMPs each. Another success case in the monitoring area is the LBA project (http://lba.inpa.gov.br/lba/), which has a vast network of PMPs in the Amazon forest, that in ten years been able to train more than 500 masters and doctors in Brazil, publishing $\sim 1000$ articles in specialized journals.

Regardless of the type of project or the mechanism that is used to implement it, projects that use a ton of carbon (sequestered or saved) as the base, guarantee the long-term presence of these stocks in nature. But most importantly, these projects require the assured quality of the data they propose to collect. These data should have Measurement, Reporting and Verification (MRV) to guarantee the technical quality of the project (e.g. see the Standard CCBA - Climate Community and VCS - Voluntary Carbon Standard). In order to guarantee viability, these projects should also have local community involvement as a goal, whether in the implementation phase or during monitoring, in order to facilitate the improvement of quality of life and the resulting socio-environmental gains. In addition to facilitating the socio-environmental benefits already outlined, the implementation of local PMPs has a powerful differential: calibrating the calculation of international methodologies with highly reliable data, collected locally and using a standardized methodology [27].

\section{Author details}

Thiago Metzker

Programa de Pós-Graduação em Ecologia, Conservação e Manejo da Vida Silvestre, Brazil

Tereza C. Spósito

Departamento de Botânica, Universidade Federal de Minas Gerais (UFMG),

CP 486, CEP 31270-970, Belo Horizonte, Brazil

Britaldo S. Filho

Departamento de Geociências, UFMG, Belo Horizonte, Brazil

Jorge A. Ahumada

Tropical Ecology Assessment and Monitoring Network, Science and Knowledge Division, Conservation International, Arlington, VA, USA

Queila S. Garcia

Departamento de Botânica, Universidade Federal de Minas Gerais (UFMG), CP 486, CEP 31270-970, Belo Horizonte, Brazil 


\section{Acknowledgement}

Support for this research was received through FAPEMIG (Fundação de Amparo à Pesquisa no Estado de Minas Gerais, Process APQ-02183-09), PELD (Long Term Ecological Research CNPq, Process 520031/98-9), the Tropical Ecology Assessment and Monitoring (TEAM) Network, a collaboration between Conservation International, the Missouri Botanical Garden, the Smithsonian Institution, and the Wildlife Conservation Society, and partially funded by these institutions, the Gordon and Betty Moore Foundation, and other donors, and USF\&WS. We thank Edgar Paiva for the illustrations in this chapter, Orbifish Global Solutions for linguistic review and the whole community of Rio Doce State Park. We thank UFMG, ECMVS and IEF (State Forestry Institute) for logistical support. T.M. received a Doctor fellowship from CAPES (Brazil) and Q.S.G. received a scholarship from CNPq (Brazil).

\section{References}

[1] FAO. Global Forest Resoucers Assessment (2005). Progress towards sustainable forest management. FAO Forestry Paper 147: Food and Agriculture Organization of the United Nations. 350 p.

[2] Keeling, H.C. \& Phillips, O.L. (2007) The global relationship between forest productivity and biomass. Global Ecol. Biogeogr. Vol. 16: 618-631.

[3] MMA (2011). Pagamento por Serviços Ambientais na Mata Atlântica: lições apreendida e desafios. Guedes, F.B. \& Seehusen, S.E. (Eds.). Série Biodiversidade 42.276 p.

[4] Corona, P. et al. (2011). Forest Ecology and Management Contribution of large-scale forest inventories to biodiversity assessment and monitoring. Forest Ecology and Management, Vol. 262: n 11, p. 2061-2069.

[5] Lund, H.G. et al. (1998). Plots, pixels, and partnerships: potential for modeling, mapping and monitoring biodiversity. In: Forest Biodiversity Research, Monitoring and Modeling: Conceptual Background and Old World Case Studies, F. Dallmeier, J.A. Comiskey, (Eds.). Man and the Biosphere Series. Vol. 20: UNESCO \& The Parthenon Publishing Group. Carnforth, Lancashire, UK.

[6] Andelman, S.J. and Willig, M. R. (2004). Networks by Design: A Revolution in Ecology. Science. Vol: 305. 2004.

[7] TEAM Network (2010). Vegetation Protocol Implementation Manual. Tropical Ecology, Assessment and Monitoring Network, Science and Knowledge Division, Conservation International. Vol. 1.5.1: 75 p.

[8] Malhi, Y. et al. (2002). An international network to understand the biomass and dynamics of Amazonian forests (RAINFOR). Journal of Vegetation Science. Vol 13: 439450.

[9] Condit, R. (1998). Tropical Forest Census Plots. Springer-Verlag, Berlin, and R. G. Landes Company, Georgetown, Texas. 
[10] TEAM Network. (2011). TEAM Network Sampling Design Guidelines. Tropical Ecology, Assessment and Monitoring Network, Science and Knowledge Division, Conservation International, Arlington, VA, USA.

[11] Clark, D.B. \& Clark, D.A. (2000). Landscape-scale variation in forest structure and biomass in a tropical rain forest. Forest Ecology and Management, Vol: 137. 185-198.

[12] Clark, D.A. (2002). Are tropical forests an important carbon sink? Reanalysis of the long-term plot data. Ecological Applications. Vol 12: 3-7.

[13] Chave, J. et al. (2004). Error propagation and scaling for tropical forest biomass estimates. Phil. Trans. R. Soc. Lond. B. Vol 359: 409-420.

[14] Schaaf L. B. et al. (2205). Incremento diamétrico e em área basal no período 1979-2000 de espécies arbóreas de uma floresta ombrófila mista localizada no sul do Paraná. Floresta. Vol 35:2.

[15] Morisita, M. (1959). Measuring of the dispersion of individuals and analysis of the distributional patterns. Men. Fac.Sci. Kyushi Univ., Ser. E (Biol.) Vol. 2: n. 4, p. 215 235.

[16] McGuinnes, W.G. (1934). The relationship between frequency index and abundance as applied to plant populations in a semi-arid region. Ecology. Washington. Vol 16: p. 263282.

[17] Vieira, S.A. (2008). Estimation of biomass and carbon stocks: the case of the Atlantic Forest. Biota Neotrop Journal. Vol. 8: n 2. ISSN 1676-0603. Available at: http://www.biotaneotropica.org.br/v8n2/pt/fullpaper?bn00108022008+en

[18] Chave, J. et al. (2005) Tree allometry and improved estimation of carbon stocks and balance in tropical forests. Oecologia. Vol 145: 87-99.

[19] Nascimento, H. E. \& Laurance, W.F. (2002). Total aboveground biomass in central Amazonian rainforest: a landscape-scale study. For. Ecol. Manage. Vol 168: 311-321.

[20] Gerwing, J. J. \& Farias, D. L. (2000). Integrating liana abundance and forest stature into an estimate of aboveground biomass for an eastern Amazonian forest. J. Trop. Ecol. Vol 16: 327-336.

[21] Higuchi, N. et al. (1998). Biomassa da parte aérea da vegetação da floresta tropical úmida de terra firme da Amazônia Brasileira. Acta Amazônica. Vol 28(2): 153-166.

[22] Tiepolo, G. et al. (2002). Measuring and monitoring carbon stocks at the Guaraquec, aba Climate Action Projetct, Paraná, Brasil. In: International Symposium on Forest Carbon Sequestration and Monitoring. Extension Series Taiwan Forestry Research Institute. Available at: http://www.spvs.org.br/download/monitoramento ingles.pdf, pp. 98- 115.

[23] Brown, S. (1997). Estimating Biomass and Biomass Change of Tropical Forests: a Primer. For the food and agriculture organization of the united nations. Rome, FAO Forestry Paper 134.

[24] Chave J. et al. (2009). Towards a worldwide wood economics spectrum. Ecology Letters. Vol 12: 351-366.

[25] Zanne A. E. et al. (2009). Data from: Towards a worldwide wood economics spectrum. Dryad Digital Repository. 
[26] Alves, L. F. (2010). Forest Ecology and Management Forest structure and live aboveground biomass variation along an elevational gradient of tropical Atlantic moist forest (Brazil). Forest Ecology and Management. Vol 260(5): 679-691. doi:10.1016/j.foreco.2010.05.023. http://dx.doi.org/10.1016/j.foreco.2010.05.023.

[27] Metzker, T. et al. (2011). Forest dynamics and carbon stocks in Rio Doce State Park - an Atlantic rainforest hotspot. Current Science. Vol 100(12): 2093-2098. Available at: http://cs-test.ias.ac.in/cs/Volumes/100/12/1855.pdf

[28] Vargas, E. et al. (2008). Biomass and carbon accumulation in a fire chronosequence of a seasonally dry tropical forest. Glob. Change Biol. Vol 14, 109-124.

[29] Delaney, M. et al. (1997). The distribution of organic carbon in major components of forests located in five life zones in Venezuela. J. Trop. Ecol. Vol 13, 697-708.

[30] DeWalt, S.J. \& Chave, J., 2004. Structure and biomass of four lowland Neotropical forests. Biotropica. Vol 36: 7-19.

[31] Baker, T.R. et al. (2004). Variation in wood density determines spatial patterns in Amazonian forest biomass. Glob. Change Biol. Vol 10: 545-562.

[32] Broadbent, E. et al. (2008). Spatial partitioning of biomass and diversity in a lowland Bolivian forest: linking field and remote sensing measurements. Forest Ecol. Manag. Vol 255: 2602-2616.

[33] Vieira, S.A., et al. (2004). Forest structure and carbon dynamics in Amazonian tropical rain forests. Oecologia. Vol 140: 468-479.

[34] Chave, J. et al. (2003). Spatial and temporal variation of biomass in a tropical forest: results from a large census plot in Panama. J. Ecol. Vol 91: 240-252.

[35] Nascimento, M.T. et al. (2007). Above-ground biomass changes over an 11-year period in an Amazon monodominant forest and two other lowland forests. Plant Ecol. Vol 192: 181-191.

[36] Rice, A.H. et al. (2004). Carbon balance and vegetation dynamics in an old-growth Amazonian forest. Ecol. Appl. Vol 14: 55-S71.

[37] Pyle, E.H. et al. (2008). Dynamics of carbon, biomass, and structure in two Amazonian forests. J. Geophys. Res. Vol 113: G00B08.

[38] Cummings, D.L. et al. (2002). Aboveground biomass and structure of rainforests in the southwestern Brazilian Amazon. Forest Ecol. Manag. Vol 163: 293-307.

[39] Castilho, C.V.et al. (2006). Variation in aboveground tree live biomass in a central Amazonian Forest: effect of soil and topography. Forest Ecol. Manag. Vol 234: 85-96.

[40] Chave, J. et al. (2001). Estimation of biomass in a Neotropical forest of French Guiana: spatial and temporal variability. J. Trop. Ecol. Vol 17: 79-96.

[41] Rolim, S.G. et al. (2005). Biomass change in an Atlantic tropical moist forest: the ENSO effect in permanent sample plots over a 22-year period. Oecologia. Vol 142: 238-246.

[42] Sheil, D. \& May, R.M. (1996). Mortality and recruitment rate evaluations in heterogeneous tropical forests. Journal of Ecology. Vol 84: 91-100.

[43] Phillips, O. L. et al. (2008). The changing Amazon forest. Philosophical Transactions of the Royal Society B Biological Sciences. Vol 363: 1819-1827. Available at: http://www.pubmedcentral.nih.gov/articlerender.fcgi?artid=2374914\&tool=pmcentrez\& rendertype $=$ abstract. 
[44] Artaxo, P. et al. (2005). Química atmosférica na Amazônia: a floresta e as emissões de queimadas controlando a composição da atmosfera amazônica. Acta Amazônica. Vol 35:185-196.

[45] Soares Filho, B. et al. (2012). Challenges for Low-Carbon Agriculture and Forest Conservation in Brazil. IDB Publications 64798, Inter-American Development Bank. 